cases were treated by prolonged immobili:ation and the result was that the muscles wasted to an extreme degree, so that when the patient got about again he always had a feeling of insecurity in the joint and the ligaments and capsule were so feeble that the accident recurred on slight provocation.

Active and passive movement should be begun when the effusion has become absorbed-generally after the end of the first week-and must be persisted in for a long time. The movement should be entirely confined to flexion and extension; it is very important that no rotation of the tibia upon the femur should be allowed. The passive movements should be precered by massage. The patient may walk about with the limb restrained by an ela tic knee-cap or a bandage which will serve to remind him that the joint is unsound and he may practise gymnastic exercises in the form of flexion and extension; these should mainly take the form of pedal exercises which strengthen the muscles of the thigh and leg. Massage should also be practised daily for half an hour or more at a time and this treatment should be continued until the capsule has once more become normal and there is no wasting of the thigh muscles; it is never safe to leave it off until then.

In cases treated on these lines good results will be obtained in a large number that are seen from the first and in many no second attack will ever occur. If the original injury was a partial displacement of the semilunar cartilage this structure may become fixed in place again and recurrence of the accident is then guarded against by strengthening the muscles of the articulation. If, on the other hand, the case is one of bruised synovial fringes, the rest and massage will lead to the disappearance of the enlargement and a cure will result.

Cases are not infrequently met with in which either the above treatment does not succeed in preventing subsequent trouble or in which the patient only comes under notice after the condition is well established and there have been several previous attacks. In these circumstances the question if anything short of operative treatment can be done will have to be decided and the applicability of apparatus must arise. It may be said here at once that no form of apparatus is any real good. The various forms of knee trusses are of no value whatever; the pad that is supposed to press back the semilunar cartilage is quite useless, for the cartilage as a rule is not in any need of being pressed back, seeing that it is separated from the head of the tibia and probably lies loose somewbere between the articular ends The only form of apparatus of any use whatever is one designed to prevent lateral bending of the knee, which is in itself a potent factor in allowing displacement of the cartilage, but apparatus of this kind should only be used when, for instance, the patient refuses operation or when it is considered inadvisable to perform one.

Concerning the operative treatment I need say little and concerning the actual steps of the operation I shall say less. The operation consists in opening the joint freely and in removing as much of the displaced cartilage as can be got at It has been recommended to suture a displaced cartilage back into place, but it is probably better to abandon this method in favour of the simpler and more radical method of removing the offending structure. The patient gets on exceedingly well without the semilunar cartilage and its removal does not affect him injuriously in any way, while if it be the real cause of the symptoms its removal prevents any chance of recurrence. A point of great practical importance, however, and one that is not sufficiently recognised is that it may be necessary to do more than remove the cartilage. In cases that have lasted a long time and have been the subject of several attacks of synovitis the synovial membrane becomes so hypertrophied that large fringes hang into the joint cavity, especially in the region of the ligamentum mucosum and the ligamenta alaria and get nipped between the bone ends, so that the symptoms may be reproduced even after complete removal of the cartilage. Before proceeding to close the wound, therefore, after the cartilage has been removed, careful search must be made for these fringes, especially behind the ligamentum patellæ, and any that are found should be snipped off. The operation in skilled hands is safe and successful, but it must never be forgotten that it is not enough merely to open the joint and to remove the cartilage or the synovial fringes and then to consider the patient cured. Most of these cases are only submitted to operation after repeated attacks of synovitis and the capsule of the joint is in a very relaxed condition and the muscles are greatly wasted through the continual attacks of inflammation and its consequent immobilisation The patient will therefore require to be put through a regular course of massage and exercises after the operation in order that the tone of the capsule may be reatored by improving the condition of the muscles surrounding the joint. The treatment, indeed, will closely approximate to that already sketched out for a case of displacement of the semilunar cartilage seen immediately after the receipt of the injury. It is very rare to get recuirence of the symptoms after the operation In the few cases in which they are known to have occurred the explanation has generally been that enlarged synovial fringes have been left behind. In some cases the real origin of the mischief has been an osteo-arthritis which has progressed in spite of the operation.

\section{REMARKS ON 50 CONSECUTIVE CASES OF PERFORATED GASTRIC AND DUO- \\ DENAL ULCER TREATED BY LAPAROTOMY.}

By T. CRISP ENGLISH, M.B. LoND., F.R.C.S. ENG.,

HUNTERIAN PROFESSOR, ROYAL COLLEGE OF SURGEONS OF ENGLAND; ASSIATANT SURGEON, GROSVENOR HOSPITAL FOR WOMEN AND CHILDREN; SURGICAL REGISTRAR, ST, GEORGE'S HOSPITAL.

THE fiftieth operation at St. George's Hospital for perforation of a gastric or duodenal ulcer was performed in June of this year. Having had the opportunity of observing and taking notes of the majority of these cases during the last six years I thought that it would be interesting to review the cases as a whole, especially in regard to certain points, such as the question of premonitory symptoms, the incidence of complications, and the after-results. For permission to use the cases I am greatly indebted to the physicians and surgeons under whose care they came. Few subjects have attracted more attention during the past few years than the condition of perforated gastric or duodenal ulcer and the number of recorded cases is now very large. In a condition of this kind, the operative treatment of which is comparatively new, it is important that cases should be reported systematically and it is unfortunate that more use cannot be made of the vast amount of material available in the wards of the large general hospitals. Cases of the greatest interest are relegated to the hospital "Reports," if such are published, or more often remain in the hospital case-books and are buried in oblivion. The value of hospital statistics, faithfully recorded. is obvious. A long series of consecutive cases, which includes the failures as well as the successes, the unfortunate cases as well as the surgical triumphs, cannot fail to give more accurate information than a collection of cases from the medical journals. It is notorious that the ways of human nature are such that the cases which find their way into the medical press are conspicuous by the absence of the correct proportion of failures. A series such as the present one possesses further value in that it represents the practices of many surgeons and the results of widely different methods.

In this paper, which I have the honour to read before you to-night, acute perforations of duodenal ulcers have betn grouped with those of gastric ulcers, as the general aspect of the cases is very similar; on the other hand, an entirely different clinical picture results with subacute or chronic perforation and no cases of this nature are included in the series. Three cases have been admitted into hospital in which no operation was performed owing to the condition of the patient being too desperate for surgical interference ; and in two instances patients were brought in dead, death having speedily occurred during the initial shock. In these latter cases the rent in the stomach wall was large and the perit oneal cavity was flooded with material from the stomach. In these 50 consecutive cases the stomach was the seat of perforation in 42 cases and the duodenum in eight cases. In the cares of perforated gastric ulcers 33 occurred in females, the average age being 26.4 years, and nine in males, with

1 A paper read before the Rogal Medical and Chirurgical Society on Nov. $24 \mathrm{th}, 1903$. 
an average age of 37.3 years; 22 , or 52 per cent., of these patients recovered. In the duodenal perforations two occurred in females, the ages being 22 years and 27 years respectively and six occurred in males, the average age being 34.6 years; two only of the eight cases recovered. The total recoveries are therefore 48 per cent. These results are

TABLE I.-50 Consecutive Cases of Perforated Gastric and Duodenul Uloer at St. Georges Hospital.

\begin{tabular}{|c|c|c|c|c|c|c|}
\hline \multirow{2}{*}{\multicolumn{3}{|c|}{ Year. }} & \multicolumn{2}{|c|}{ Gastric ulcer. } & \multicolumn{2}{|c|}{ Dundenal nlcer. } \\
\hline & & & Cases. & Recovered. & Cases. & Kecuvered. \\
\hline 1892... & $\ldots$ & ... & 1 & 0 & - & - \\
\hline $1893 . .$. & $\ldots$ & ... & 1 & 0 & - & - \\
\hline $1894 \ldots$ & $\ldots$ & ... & 3 & 1 & 2 & 0 \\
\hline $1895 .$. & $\ldots$ & ... & 3 & 1 & - & - \\
\hline $1896 \ldots$ & $\ldots$ & ... & 3 & 2 & 1 & 0 \\
\hline $1897 \ldots$ & $\ldots$ & ... & 5 & 3 & 一 & 一 \\
\hline $1893 \ldots$ & $\ldots$ & $\ldots$ & 6 & 1 & 2 & 1 \\
\hline $1899 . .$. & $\ldots$ & ... & 3 & 2 & - & - \\
\hline $1900 \ldots$ & $\ldots$ & ... & 4 & 2 & 一 & - \\
\hline $1901 . .$. & $\ldots$ & ... & 2 & 1 & 1 & 1 \\
\hline $1902 \ldots$ & ... & $\ldots$ & 4 & 3 & 2 & 0 \\
\hline $1903 \ldots$ & $\cdots$ & ... & 7 & 6 & 一 & - \\
\hline \multicolumn{3}{|c|}{ Total } & .. 42 & 22 & 8 & 2 \\
\hline
\end{tabular}

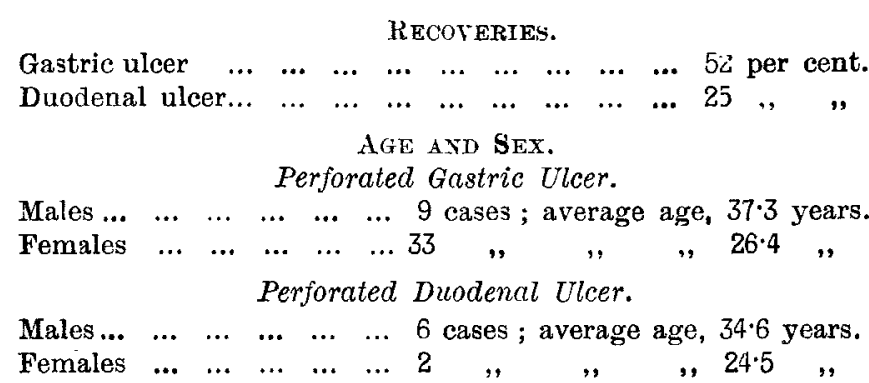

very encouraging, more especially as it is found that the mortality is steadily diminishing. Three out of the first ten cases recovered, whilst of the seven cases admitted during the present year six have recovered. This improvement is doubtless due to the earlier recognition of the condition, to earlier operations, and to the greater care expended in the cleansing of the peritoneal cavity.

The first oparation of this nature at St. George's Hospital was performed in December, 1892, although several cases of subphrenic abscess had been surgically treated before this date. The case presents several points of interest. The patient was a woman, aged 26 years, and the abdomen was opened 14 hours after the onset of symptoms. A perforation of the stomach was found in the centre of an area of dense induration three inches in diameter. Invagination of the perforation was impossible and excision was equally out of the question; the abdomen was therefore irrigated and the perforation was attached to the upper part of the wound, a drainage-tube being inserted. Bilateral parotitis developed during the first week after operation and suppuration occurred in both glands. Pulmonary symptoms developed later and the left lung was explored, with a negative result. The patient survived until the forty-third day after operation and at the necropsy a small abscess was found between the base of the left lung and the diaphragm.

The first successful case occurred in April, 1894. The patient was a female, aged 41 years, and the perforation was a small one in a chronic ulcer near the pylorus.

The question of premonitory symptoms is one of the highest importance, for it is found that in a certain proportion of the cases premonitory symptoms do occur although they are hard to recognise. My attention was more especially drawn to this point by having seen three patients in whom perforation occurred whilst they were under treatment in hospital. In order to gain further information on this point I analysed, firstly, the previous history; and, secondly, the symptoms immediately preceding perforation. In regard to the first point I found the following results. In five cases there was no history of previous gastric trouble of any kind; in 34 cases there had been definite dyspepsia or gastric ulceration, amatemcsis having occurret in eight of these cases. In six cases it was stated that though there had once been dyspepsia this had not existed for some time before perforation ; in five cases no information is given on the point. In

TABLe II.-Previous History of the Cases.

$\begin{array}{llllllllllll}\text { No gastric symptoms } \ldots & \ldots & \ldots & \ldots & \ldots & \ldots & \ldots & \ldots & \ldots & \ldots & 5\end{array}$ Definite gastric symptoms without bæmatemesis ... $\begin{array}{llllllllllllll}\text { Hæmatemeris } & \ldots & \ldots & \ldots & \ldots & \ldots & \ldots & \ldots & \ldots & \ldots & \ldots & \ldots & 8\end{array}$ $\begin{array}{lllllllllllll}\text { Former dyspepsia } & \ldots & \ldots & \ldots & \ldots & \ldots & \ldots & \ldots & \ldots & \ldots & \ldots & \ldots & 6\end{array}$ $\begin{array}{lllllllllllllllll}\text { Not known } & \ldots & \ldots & \ldots & \ldots & \ldots & \ldots & \ldots & \ldots & \ldots & \ldots & \ldots & \ldots & \ldots & & \end{array}$

Symptoms immediately preceding Perforation.

$\begin{array}{llllllllllll}\text { No special sumptoms } \ldots & \ldots & \ldots & \ldots & \ldots & \ldots & \ldots & \ldots & \ldots & \ldots & \ldots & 40\end{array}$ $\begin{array}{llllllllllllll}\text { Hæmatemesis } & \ldots & \ldots & \ldots & \ldots & \ldots & \ldots & \ldots & \ldots & \ldots & \ldots & \ldots & \ldots & 2\end{array}$

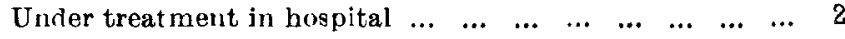

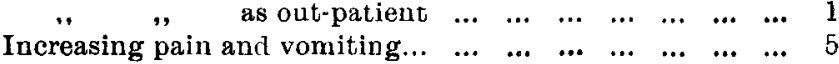

22 per cent., therefore, symptoms had been completely latent before the actual rupture, whilst in many of the others the dyspepsia had been of a slight nature, not requiring any serious medical treatment.

A study of the symptoms immediately preceding the onset of the violent pain characteristic of the moment of perforation is of more importance. As is well known, in the great majority of cases the onset is sudden and without warning. In ten of the cases, however, this was not so, the condition then usually being progressive increase of $p=i n$ and vomiting for a short period before perforation, this period being sometimes a few hours, sometimes two or three days. It one case hæmatemesis had occurred four times in the preceding three weeks. In another case the patient had just come to the out-patient department to be treated for gastric ulcer and was waiting at the dispensary for her medicine wh $+n$ perforation occurred. A second case in which hæmatemesis preceded perforation is referred to below. The compurative rarenes of this association is probably due to the careful treatment to which patients recovering from hæmatemesis are subjected. In ten cases I made inquiries as to the menstrual history of the patient but found no evidence that perforation is more likely to occur shortly before and during menstruation than at any other period; in two cases only did the conditions coincide. Hæmatemesis, on the other hand, undoubtedly is more frequent ju-t betore the onset of menstruation, a fact which is probably explained by the higher blood-pressure at this time.

The cases in which perforation occurred in hospital must be referred to in greater detail. All three patients were men and the similarity in the cases is very striking.

CASE 1. - This patient was a man, aged 48 years. He had suffered from dyspepsia for 12 years and for the six months before admission there had been severe epigastric pain with frequent vomiting and rapid loss of weight. On admission the stomach was greatly dilated and there was marked epigastric tenderness. During the first two days there was moderate pain but no vomiting; on the third day the pain was worse and vomiting occurred twice; on the fourth day the pain was less but there was more superficial tenderness in the epigastrium. Daring the evening of this day the pain gradually became worse and then suddenly the patient was selzed with the most intense pain and became extremely collapsed. Six hours later a ragged irregular perforation on the anterior surface of the stomach close to the pylorus was sutured. Progress was satisfactory until the eleventh day after operation, when prof use melæna set in and death occurred on the fifteenth day. The necropsy showed that a duodenal ulcer had perforated the gastroduodenal artery.

CASE 2. - The patient was a man, aged 37 years, who had been sent to hospital as a case of carcinoma of the pylorus. There were marked dilatation of the stomach and an irregular mass in the right hypochondrium. The patient was quite comfortable, except after taking food which caused pain and usually vomiting. Tenderness over the swelling was present throughout. On the evening of the third day symptoms of perforation occurred, followed by great collapse and death a few hours later. The lesion proved to be a large chronic ulcer with a small perforation on the lesser curvature.

CASE 3. - This case occurred three months ago. The patient, aged 63 years, was also supposed to be the subject of carcinoma of the pylorus. There had been much pain after food for sir months, with rapid loss of weight and 
vomiting characteristic of dilatation of the stomach for a month. On admission there were superficial tenderness over the upper part of the right rectus muscle and gastric peristalsis extending to a line one and a half inches below the umbilicus. On the second day there was constant pain, aggravated by milk and soup. On the third day, 44 hours after admission, a sudden attack of hæmatemesis occurred, a pint of dark blood and clots being vomited. Nine hours later, whilst the man was reading a newspaper, sudden agonising pain occurred in the right hypochondriac and scapular regions. The signs of perforation were obvions and the abdomen was opened two hours later; a small pin-hole perforation in the floor of a large pyloric ulcer was found, but unfortunately the patient died from syncope at the close of the operation.

A careful study of these cases leads us to the following conclusions. Premonitory symptoms are most likely to occur in cases of chronic and marked ulceration; such symptoms are progressive increase in discomfort and pain after taking food of any kind, greater frequency of vomiting, and increase of the superficial and deep tenderness in the epigastrium. When such conditions are found active and deep ulceration with the danger of perforation should at once be suspected and no food of any kind should be administered by the mouth. The patient should be kept quiet in bed and morphia especially should be avoided owing to the danger of masking the symptoms of perforation should this occur.

In regard to symptoms of perforation, the onset was abrupt in the great majority of cases, the patient being occupied with the ordinary duties of life at the time of perforation. In several instances rupture had been determined by some extra exertion or the ingestion of food; in one case vomiting had occurred just before. On the other hand, in nine cases verforation occurred whilst the patient was in bed. The severity of the initial pain is almost constant and highly characteristic of perforation. This sudden, terrible, intolerable pain is rarely met with in any other condition and cannot in its full intensity be simulated by neurotic subjects. Although as a general rule we must rely rather on what we see than on what we hear in these cases, a history of pain of this character appears to be of real value in forming a diagnosis. The situation of the pain is no guide to the situation of the lesion. In perforations of the stomach the pain is often most intense in the lower part of the abdomen, the gush of stomach contents falling towards the pelvis. It is notorious that in many cases of perforated duodenal ulcer the pain is most marked in the right iliac fossa and acute appendicitis is closely simnlated. The intensity of the collapse was found to bear a fairly constant relation to the size of the perforation; and similarly, the larger the tear the more free gas in the peritoneal cavity.

Somewhat discordant statements have been made as to the frequency with which vomiting forms one of the symptoms of perforation. One well-known authority states that vomiting is usually absent, whilst others have suggested that it is a mechanical impossibility if the rent is at all large ; Finney found it recorded in 40 per cent. of the cases and Fenwick in 29 per rent. In the present series vomiting occurred in 37 cases, was absent in ten, and was not mentioned in three; in other words, it oc urred in over 75 per cent. of the cases. Generally speaking, it occurred shortly after perforation in the majority of cases and did not recur after the first few hours. In five instances, however, vomiting did not take place until an interval of two hours or more after the onset of the primary pain. Further, it was usually noticed that in the fatal cases, in which vomiting had been absent for some hours before operation, it reappeared and persisted after recovery from the anæsthetic.

The stage of reaction following the stage of collapse was met with in a large number of the cases. 'The degree of reaction varied but it was often well marked and then latency of symptoms formed a prominent feature. The primary collapse was recovered from, the pain subsided. the vomiting ceased, and two of the patients even walked into the hospital with their peritoneal cavities bathed in gastric contents; occasionally the pulse became normal in trequency and tension, the temperature normal, and no nnusual physical signs were discoverable in the abdomen. This period has been well described as the quiescent period, or the period of repose, and should the true state of affairs not be grasped disaster may follow. If the patient is first seen in this stage, as frequently happens, a serious view may not be taken of the case and a fatal delay may result. The treacherous calm is followed by storm, the acute symptoms return, and the presence of acute peritonitis becomes unmistakeable. Numerous instances might be related of this The fullowing two cases, however, will illustrate the condition well.

CASE 4.-A man, aged 36 years, walked into St. George's Hospital complaining of "stomach ache" which he attributed to having eaten half a pound of unripe cherries on the previous evening. The pain had come on suduenly two hours before he came to hospital and had been severe and accompanied by vomiting. When sten his general condition was perfectly good. He complinined of slight colicky pain about the umbilicus; the pulse was 76 , the temperature was $98.4^{\circ} \mathrm{F}$., and the abdomen was soft, without tenderness or rigidity. He was admitted and carefully watched. Slowly but progressively the pulse increased in frequency-a point of especial importance. At 6 P. M. it was 96 , at 10 P.M. it was 110 , at midnight it was 116 , and at 2 A.M. it was 128 . The abdomen became board.like and tender and vomiting returned. Laparotomy was performed, revealing a perforated duodenal ulcer with early general peritonitis ; the perforation was sutured, the peritoneum was cleansed, and the man made an excellent recovery.

CASE 5.-This case was that of a young woman, aged 22 yeare, who was sent to hospital with a history of sudden abdominal pain and collapse withont vomiting. On admission there was nothing in her appearance to suggest that she was ill. Her pulse was 72 and of good quality, her temperature was $986^{\circ} \mathrm{F}$, and the abdomen presented no tenderness, rigidity, distension, or abnormality on percussion. A few hours later her pulse became more frequent and the abdomen tender and board-like. Laparotomy was performed and a perforated gastric ulcer was found.

Having thus emphasised the latency of symptoms during the period of reaction the next point which I wish to raise is the effect of stimulants in producing temporary improvement in the patient's condition and in masking the gravity of the case. The quiescent period, of course, occurs quite apart from the administration of morphia or stimulants, although these measures naturally intensify it The action of morphia in this respect is universally known but $I$ believe that stimulants will produce a similar deceptive improvement, especially in the form of the large doses of brandy so often administered by sympathetic relatives and friends. In Case 5 the medical man had injected 12 minims of solution of strychnine owing to the profound collapse in which he had found the patient. This treatment was undoubtedly beneficial but I think contributed largely to the complete quiescence of symptoms observed a lew hours later.

The condition of the hepatic dulness appears to be inseparably connected with the notes of cases of this kind. It forms an obvious and striking physical sign but experience shows that it is of comparatively little value and likely to mislead if relied upon. It has been weighed in the balance and found wanting. Cases of uncomplicated gastric ulcer without any distension of the abdomen have been published in which the liver dulness has been completely absent and in which laparotomy has proved that no perforation existed. The condition of the liver dulness is definitely stated in 43 of the cases; it was normal in 11 cases, completely absent in 12 , and diminished in 20 cases. In several instances in which it was diminished this change was found to be limited by the falciform ligament and then dulness was more often absent to the left than to the right of the ligament. It has been suggested that loss of the hepatic dulness as far back as the mid-axillary line can only be produced by the presence of free gas in the peritoneal cavity, not by other conditions such as distended intestine. In order to test the accuracy of this statement I carefally examined the liver dulness in ten cases of perforation; in seven of these it was diminished or absent, and in four of the cases this diminution extended to the mid-axillary line. On the other hand I discovered a similar condition in two cases in which the abdomen was opened but no perforation was found. This sign, therefore, seems equally unreliable. The exact cause of this change in the liver dulness, when not due to the pre-ence of free gas in the peritoneal cavity, is extremely difficult to explain and several theories have betn advanced. It seems unlikely that the distended colon can often lie actually in front of the liver, for it is very rare at necropsies of any kind to find intestine between the liver and the anterior abdominal wall; in one of the fatal cases in 
this series, however, in which liver dulness was noted as absent before operation, the colon was found in front of, and considerably compressing, the right lobe of the liver.

It has been stated that the presence of a well-marked area of stomach resonance in the left hypochondrium contra. indicates perforation of the stomach. It was, however, frequently noted during the operation that the stomach was distended with gas and sometimes greatly distended when the perforation was small or valvular. The extent of gastric resonance is therefore of no diagnostic value. I may here mention that in two cases seen shortly after perforation I was struck by the fact that sweating, though present over other parts, was more intense by far over the epigastrinm.

The situation of the perforation is shown in the accompanying diagram. During operation it is of ten very difficult

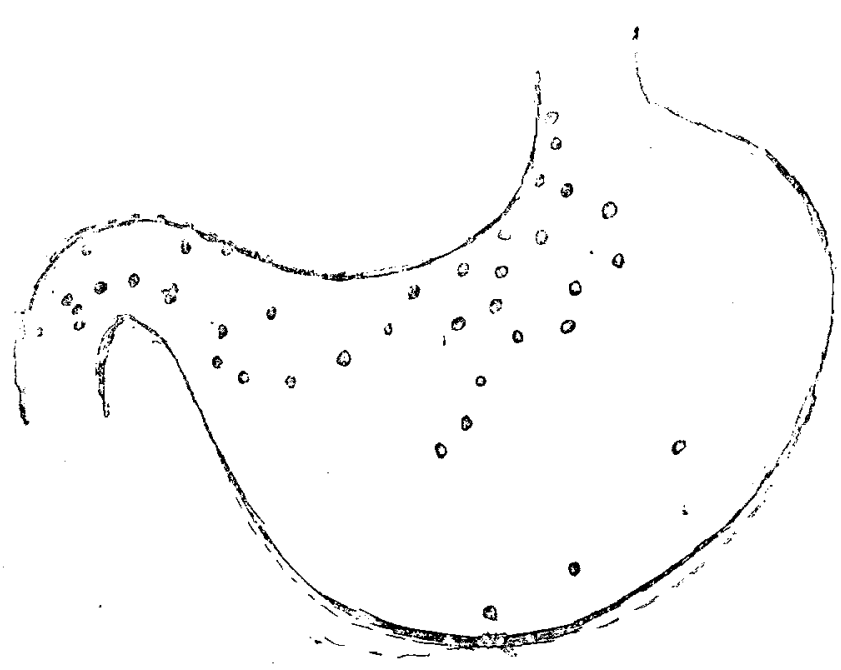

Diagram showing the situatinn of ulcers on the anterior wall of the stomach and the duodenum.

to be certain as to the exact position of the ulcer, more especially when there are many adhesions or much lymph around, and discrepancies upon this point are frequently found in the accounts of the operations and the post-mortem reports. The diagram shows that perforations most commonly take place in ulcers situated close to the lesser curvature and are rather more frequent towards the cardiac than the pyloric end of the stomach. On the other hand perforating ulcers close to the greater curvature are comparatively rare. Five of the ulcers occurred on the posterior wall, close to the pylorus ; the rents were usually large and the gastric contents had escaped through the foramen of Winslow into the greater sac of the peritoneum. The duodenal perforations all occurred in the first part of the duodenum, six on the anterior wall and two on the upper and posterior wall.

The number of instances in which perforated duodenal ulcers have been successfully sutured is still so small that details of two cases in this series may here be referred to. The first case has already been mentioned as an example of the "latent period" or period of repose; it has been published in detail elsewhere. ${ }^{2}$ The second case occurred in a female, aged 22 years, with a history of old but not recent indigestion. Eight hours after taking some aperient pills she was suddenly seized with agonising pain, felt at first in the right hypochondrium and later spreading over the entire abdomen. She felt sick but no vomiting occurred. The pain continued and morphia was given; the bowels acted scantily after an enema on the third day, when she was admitted into hospital. Her condition was then masked by morphia; pain was referred vaguely to the right side; the abdomen was hard, rigid, and tympanitic all over, im. mobile, but not much distended; liver dulne:s was diminished. Laparotomy was performed about 68 hours after the onset of symptoms and free gas with foodstuff was found in the peritoneal cavity. A small perforation in the first part of the duodenum was discovered and occluded by a purse-string suture, strengthened by four Lembert stitches. The peritoneum was thoroughly irrigated and she was discharged four weeks later after an uneventful convalescence.

The possibility of saving the patient's life even in the most desperate cases is further illustrated by a case in which a

2 The Lancet, March 29th, 1902, p. 890. perforated gastric ulcer was successfully treated 72 hours after the onset of symptoms. The case is a remarkable one for there was intense general peritonitis and the patient's. condition before operation was so precarious that surgical interference seemed scarcely justifiable.

The in idence of complications arising after operation will next be discussed. Of the 24 cases in which the patients recovered definite complications occurred after operation in 13 , whilst in the fatal cases in which the patients survived the first 24 hours after operation complications developed in eight. In the two cases in which perforated duodenal ulcers were successfully satured the patients recovered without complications ; empyema was present in one of the fatal cases. It appears that in more than half of the successful cases complications may be expected during the period of convalescence, and, further, that complications are often multiple and are more commonly noticed after than during the first week.

\section{TabLe III.-Inoidence of Complications.}

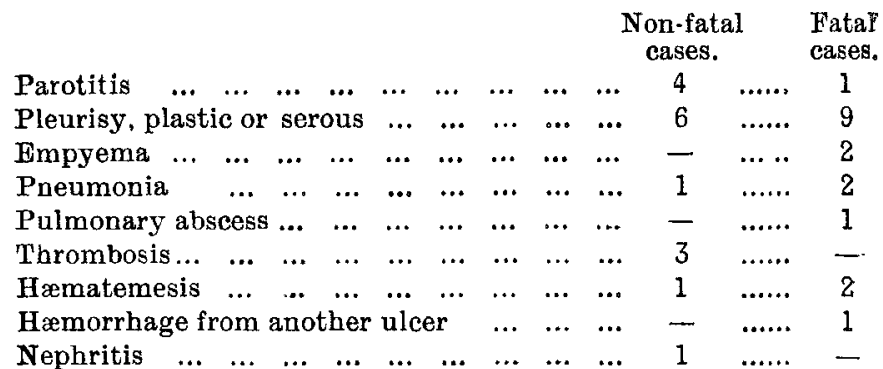

Inflammation of the parotid gland occurred in five cases. being bilateral in two and involving the gland on the left side in the other three. It was first noticed on the second. third, fifth, sixth, and sixteenth days respectively and in the bilateral cases the onset of inflammation on the two sides was separated by an interval of two days. Suppuration-a very unusual event in these cases-occurred in both glands in the first case operated upon at St. George's Hospital ; the right parotid had become inflamed on the second day and the left on the fourth day, and pus was discharged from both ears on the ninth day. Incisions were made and the resulting sinuses persisted until death six weeks later.

No definite relation to the absence of feeding by the mouth is noticed, three of the patients in whom this complication occurred having had food by the mouth for more than 24 hours. Mr. B. N. Tebbs, of St. George's Hospital, has very kindly given me figures relating to the incidence of nonspecific parotitis. Of 32 cases occurring in this bospital during the last ten years 21 followed operation upon, or disease of, the stomach.

Uncomplicated gastric ulcer. Cases.

Perforated gastric ulcer..

Excision of gastric ulcer

$\begin{array}{lllllllll}\ldots & \ldots & \ldots & \ldots & \ldots & \ldots & \ldots & \ldots\end{array}$ Total 1 4 21

Pleurisy is by far the commonest complication, occurring in six of the successful cases and being found in 11 of the $2 \mathrm{~L}$ cases in which the chest was examined post mortem. As would be expected, the left side was most commonly involved; the actual figures are-both sides, five cases: left side, ten cases ; right side, two cases. The pleurisy was usually of the dry fibrinous variety (11 cases) and limited to the diaphragmatic area. In two fatal cases, however, an empyema was present. It seems probable that the pleurisy is often due to the transmission of toxic products through the diaphragm and not to the presence of micro-organisms for the effused fluid is usually sterile and empyema is uncommon. This is illustrated by a case which occurred two years ago.

CAsE 6.-The patient was a female, aged 23 years: On the fifth day after operation friction was heard in the left lower axillary region; this was followed by signs of effusion into the pleural cavity and on the eleventh day the pleura was aspirated and 21 ounces of serous fluid were withdrawn. Microscopically this was found to contain a very large number of highly active leucocytes, whilst cultures made from the fluid proved absolutely sterile. The temperature remained high and irregular and rigors occurred. An empyema was suspected and the pleural cavity was opened 
in the mid-axillary line on the sixteenth day. Only clear tuid, however, was found and so the diaphragm was punctured. This led to the discovery of a large subdiaphragmatic abscess containing a quantity of very foul pus.

Amongst the other complications are the following. Thrombosis occurred in three cases, the left external saphena vein being involved twice, and the deep veins of the left leg in the other case ; the symptom was first noticed on the fourteenth, sixteenth, and seventeenth days respectively. Severe hæmatemesis occurred in three cases, two of which ended fatally; death in one case was due to blood inhalation during vomiting, the trachea and bronchi being found full of blood post mortem. Reference has already been made to a case in which severe hæmorrhage from perforation of the gastro-duodenal artery by a duodenal ulcer proved fatal 11 days after successful suture of a perforated gastric ulcer. Hæmaturia and albuminuria were noticed on the seventh day in a female, aged 28 years, although as far as could be ascertained this condition had not existed before. Albumin and renal casts with a few pus cells were present in the urine for six weeks, at the end of which time the urine became. normal.

All the symptom; and physical signs of perforation may be presented and yet the stomach may be found intact when the abdomen is opened. Such cases must occur in the practice of any hospital or of any surgeon of experience, for undoubtedly the correct treatment is to explore whenever perforation is suspected A small incision above the umbilicus will at once decide the question and involves practically no risk in itself, whilst a few hours of delay may be sufficient to make operation futile. 'These cases may be divided into two classes-those in which some other peritoneal lesion is found and those in which nothing abnormal is discovered. I have the notes of seven such cases. All the cases occurred in young females with histories of gastric trouble; the symptoms and signs pointed to perforation of the stomach and operation proved that this had not occurred. In three cases no abnormality of any kind was discovered; one case was especially interesting as she was admitted at exactly the same time as another patient with exactly identical symptoms, which proved in the latter case to be due to a perforated gastric ulcer. Another patient, a highly neurotic woman, aged 28 years, who had already had laparotomy performed twice, was admitted in the middle of the night with acute abdominal symptoms. In the fourth case nothing was discovered beyond some blood-stained cedema of the gastric attachment of the omentum. In the fifth case the peritoneal cavity contained blood-stained fluid; the pelvis was examined through a second incision and apparently rupture of a small ovarian cyst was the cause of the condition. The sixth and seventi cases proved fatal. In one the abdomen was full of odourless turbid serum and a most careful search failed to reveal the source of the infection; the stomach was most certainly intact; no necropsy was performed. The other was a case of acute appendicitis with general peritonitis in a young dyspeptic girl in whom all the physical signs were most intense in the epigastric region. The reverse condition, of course, is more common-namely, the simulation of appendicitis by a perforation of the pyloric end of the stomach or duodenum, owing to the downward gush of fluid, and in four cases in this series the primary incision was made over the region of the appendix. It is interesting to note that in two of the three cases in which there was no intraabdominal lesion the symptoms occurred shortly before the onset of the menstrual period. I bave seen several other cases in which neurotic women have presented acute abdominal symptoms at this time; the clinical picture of perforated gastric ulcer may be closely simulated, but, generally speaking, there are not the severe collapse and intense pain at the outset and constitutional disturbance is not so marked. The symptoms clear up with the onset of menstruation. It would be interesting to hear of other cases of this nature.

The frequency with which ulcers are present in other parts of the stomach or duodenum is well illustrated by examina. tion of the fatal cases. In 13 of the 21 cases in which necropsies were performed other peptic ulcers were prokent and it is quite possible that small ulcers may have been overlooked. In two instances four ulcers were present in addition to the one which had perforated. Their most common situation was exactly opposite the peforated ulcer. Although no cases of double perforation occurred, in one instance a second acute ulcer of the perfurating type
was found to have reached the peritoneal coat of the stomach.

In regard to the details of the operations it is found that general irrigation of the peritoneal cavity was employed in 31 cases, local irrigation in nine cases, and in the remainder sponging only was relied upon; with each of the three methods the mortality was the same-namely, about 50 per cent. A further point brought out by a study of the cases is the increasing tendency to dispense with drainage. This is a question upon which surgeons differ greatly and is one well worthy of discussion. The difficulty in securely closing the perforation in deeply seated ulcers was frequently found to be diminished by the preliminary separation of adhesions to the liver and surrounding parts and by the use of cleft palate needles: the line of suture was strengthened in six cases by omental grafts or plugs and in three cases by a similar use of masses of lymph. In a case in which the perforation was deeply placed near the csophageal opening and stitching was impossible owing to the friability of the surrounding gastric wall, strips of gauze were passed down to the ulcer; no further escape of gastric contents occurred and an uneventful recovery followed.

In conclusion reference must be made to the after condition of the patients. Do the symptoms of gastric ulcer recur or is the patient cured by operation? The question is one of practical importance, for certain authorities recommend that a posterior gastro-enterostomy should be performed after the perforated ulcer has been dealt with if the patient's cundition will bear it. This operation would be exceedingly difficult, or perhaps impossible, if attempted at a later date, and so it is urged that it should be done at once in order to complete the patient's cure. Regarding the matter from a theoretical point of view we might expect the symptoms of ulceration to recur if the perforation be simply sutured. These ulcers are known to be usually multiple and the local conditions which favour ulceration still exist. In practice we find that this is not the case; the after-results are surprisingly good. Daring the last summer I have written to each of the 24 patients in the successful cases. An investigation of this kind is always difficult, for hospital patients of all kinds, and domestic servants in particular, are constantly changing their address and so are readily lost sight of. I was able, however, to trace 17 of the 24 patients. The reports of these cases may be summarised as follows. In 11 cases there had been no return of gastric symptoms of any kind and the patients had been quite well since the operation; two had married and had had children; and in four cases dyspeptic symptoms were complained of, two being readmitted into hospital for short pariods. The point which I wish to emphasise here is that the symptoms were characteristic of dyspepsia and not of gastric vilcer; the pain was of a dull, aching, diffuse character and in no case was there vomiting or hæmatemesis. One patient came under treatment one and a half years atter operation for odema and superficial varicose veins of the leg; this case had been complicated by thrombosis and was satisfactorily treated by an elastic stocking; there were no gastric symptoms. Another patient was recently seen seven years after opera. tion. She was sulfering from congestive dysmenorrhoea and the pelvic organs were found to be extensively matted by firm adhesions ; slight peristalsis of the intertinal coils was also visible through the abdominal wall. She had been married for five years and was sterile. It seems highly probable that in this case the pelvic peritonitis, with the subsequent dysmenorrhœa and sterilitiy, dated from the gastric perforation. The number of cases is small but the results point conclusively to the fact that the great majority of the patients are cured of their gastric ulcers if they survive the primary operation. Dyspeptic symptoms occur in a small proportion of cases and are readily amenable to medical treatment. Gastro-enterostomy is therefore unnecessary ; in any case there are many arguments again $t$ its immediate use in cases of perforation. It materially increases the duration of the operation and rapidity is essential if the patient is to have her best chance. In itself the operation involves an increased risk; the parts are in the worst possible condition for a complicated plastic operation; and fically, as I have said, it is unnecessary. I have already referred to a patient who died from hæmorrhage from a duodenal ulcer on the fifteenth day after suture of a ruptured gastric ulcer. In this case it is possible that a gastro-enterostomy might have checked the progress of the duodenal ulcer and prevented the fatal bæmorrhage ; but the 
case is quite an exceptional one and forms no argument for the routine performance of gastro-enterostumy.

TABLE IV.-After Condution of the Successful Cases.

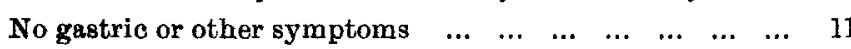
$\begin{array}{lllllll}\text { Gedema of the leg following thrombosis } & \ldots & \ldots & \ldots & \ldots & \ldots & 1\end{array}$

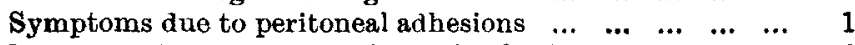

$\begin{array}{lllllll}\text { Dyspepsia (no symptoms of gastric ulcer) } & \ldots & \ldots & \ldots & \ldots & 4\end{array}$

$\begin{array}{llllllllllllll}\text { Not traced } & \ldots & \ldots & \ldots & \ldots & \ldots & \ldots & \ldots & \ldots & \ldots & \ldots & \ldots & \ldots & 7\end{array}$

Total

Grosvenor-street, $\mathbf{w}$

$\longrightarrow$

\section{CLEFT-PALATE AND HARE-LIP; THE EARLIER OPERATION ON THE PALATE.}

BY EDMUND OWEN, F.R.C.S. ENG.,

CONSULTING SURGEON TO ST. MARY'S HOSPITAL AND TO THE HOSPITAL FOR SICK CMILDREN, GREAT ORMOND STREET.

For about 20 of the years that I was upon the active staff of the Hospital for Sick Children, it was my practice to operate upon hare-lip in early infancy but to postpone the treatment of the cleft-palate until the child was two, three or four years old. This plan of procedure was, indeed, a very general one. It had been adopted for several reasons-the fissured lip was dealt with before the cleft-palate because experience had shown that if the infant were in a fair state of health he could confidently be trusted to stand the shock of that lesser operation. Moreover, it was thought that if the gap in the lip were soundly closed the anterior part of the palatine cleft would keep on growing narrower up to the time of the operation on the palate. The palatine cleft was left uninterfered with because it was thought that at this tender age the infant would not be likely to survive the shock of the prolonged operation for its closure, accompanied, as it must be, by a very considerable loss of blood.

FIG. 1 .

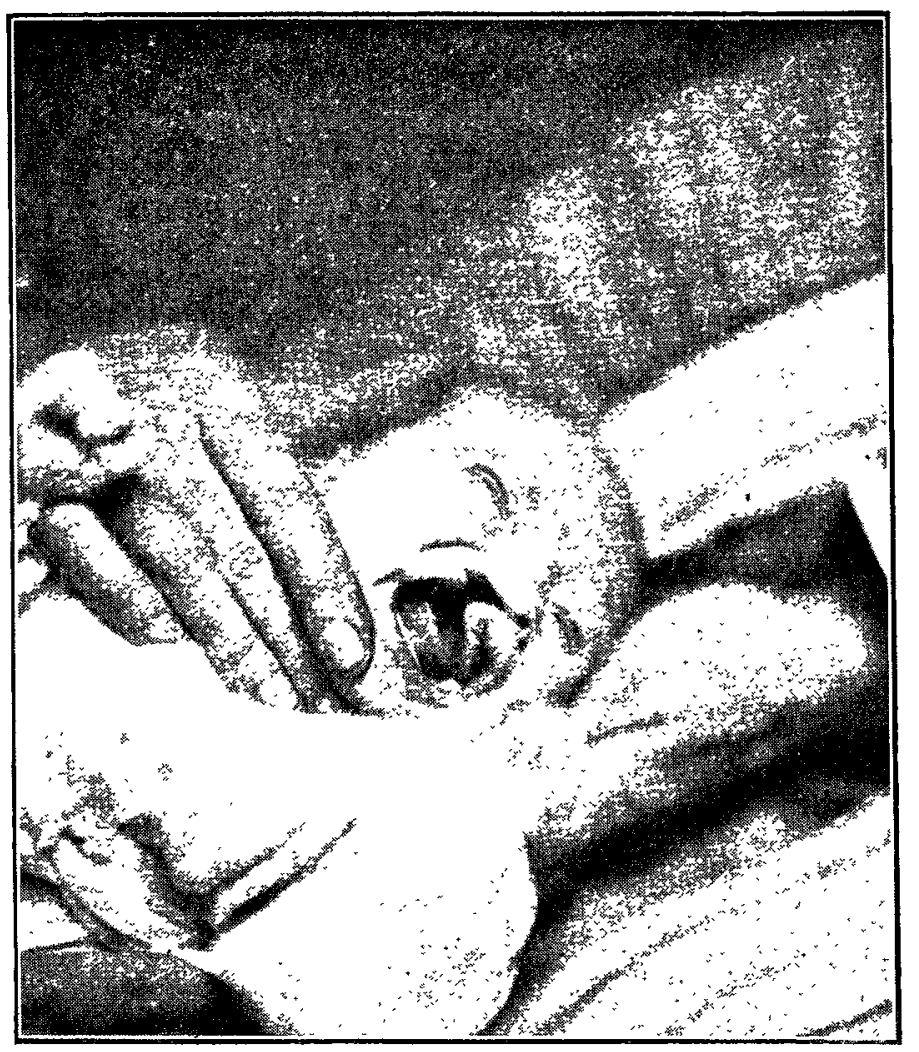

Cleft-palate and hare-lip in an infant aged three months.

A few years ago my alitention was directed by my colleague at St Mary's Hospital, Mr. Morton A. Smale, to the method of treatment of cleft-palate which he had seen Dr. Brophy adopt at Chicago. Dr. Brophy not only operated upon the palate before the lip in early infancy, but he dealt with the palatine cleft in an uriomal and very radical manner, namely, by boldly thrusting the maxillary and palate bones together in the middle line.

Since becoming more fully acquainted with Dr. Brophy's method I have cordially adopted it, and though I realise that it is not unattended with risk, still I consider the advantages associated with it are so great that the extra risk may be unhesitatingly accepted.

By way of illustrating Dr. Brophy's method, I will briefly describe it as carried out in the case of a male infant whom Dr. D. Bennie Hewat recently sent to me from Cape Town. The infant was three months old on Feb. 3rd, 1903, the day that I first saw him. He was a miserable-looking object, and he weighed but six and a half pounds. When he cried, the mouth and naso-pharynx showed as one large cavity (Fig. 1) which the maxillary processes very ineffectually attempted to separate. Indeed, for so small an infant, the cleft was enormous-which is much the same thing as saying that the horizontal processes of the maxillary and palatine bones offered but scanty material for the formation of a roof to the month. This is not shown in the illustration, but the width of the gap in the lip more than suggests that the palatine cleft was a wide one. Its exact width, as determined by a pair of compasses, is shown in Fig. 2. The

FIG. 2.

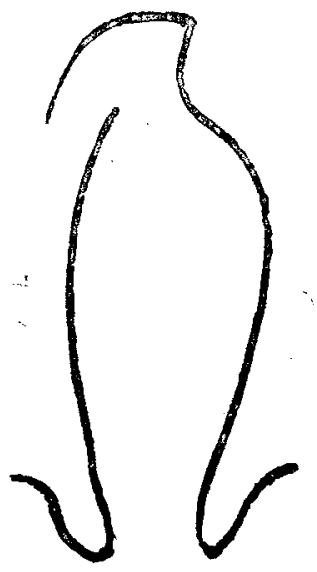
Cleft of palate extending into the right nostril in an infant aged
three months.

cleft extended into the right nostril. The vomer was adherent to the left maxillary process.

Before the operation, a warm enema of peptonised beef-tea with a little brandy was given, and the infant was swaddled in Gamgee tissue. The operating-table was made almost as high as an orcinary mantel-shelf, so that the surgeon might carry on his work without having to stoop too much. Chloroform was the anæsthetic, which Mr. Henry Davis gave on a small mask. The tongue was drawn forward by a long suture, and the mouth was kept open by a modified Smith's gag.

The operation was begun by paring the edges of the cleft, and after this I tried, but ineffectually, to thrust the maxillæ towards each other by firm pressure with the fingers and thumb. Next, following Dr. Brophy's directions, I raised the cheek, and, by a strong curved needle in a handle, passed a silk suture across the nasal fossa, above the level of the hinder part of the alveolar processes. The end of a thick silver wire was then hooked on to this suture, and, by pulling on the latter, the wire was made to take its place. The wire suture thus lay above the horizontal processes of the palate bones, where it could be seen through the cleft. Similarly, a wire suture was taken through the maxillæ above the front part of the cleft. Two small, oblong leaden plates, with a hole drilled near each end, had already been prepared, and one of them was then laid along the outside of the right maxilla, under the cheek, the end of the hinder wire being passed through the posterior hole, and the end of the front wire through the anterior hole. The right ends of the wires were then twisted together from left to right, the plate being closely applied against the maxilla, after which the twisted ends of the wires were pressed down flat. The ends of the wires under the left cheek were then similarly treated, and as they were being twisted up the maxilla were squeezed together, or, rather, another vigorous attempt was made to squeeze them together. But I could not move them. So, in accordance with Dr. Brophy's advice, I then incised the mucous membrane over each malar process and, introducing a scalpel, divided 